\title{
Flexible Zinc-Manganese Dioxide Alkaline Batteries Based on Kelp Electrolytes
}

\author{
Shuyang Wang1, Xiayue Fan² \\ ${ }^{1}$ Shanghai Shangde Experimental School, Shanghai, China \\ ${ }^{2}$ Key Laboratory of Advanced Ceramics and Machining Technology (Ministry of Education), School of Materials Science and \\ Engineering, Tianjin University, Tianjin, China \\ Email: xyfan@tju.edu.cn
}

How to cite this paper: Wang, S.Y. and Fan, X.Y. (2019) Flexible Zinc-Manganese Dioxide Alkaline Batteries Based on Kelp Electrolytes. Journal of Materials Science and Chemical Engineering, 7, 19-28. https://doi.org/10.4236/msce.2019.712003

Received: November 12, 2019

Accepted: December 9, 2019

Published: December 12, 2019

Copyright () 2019 by author(s) and Scientific Research Publishing Inc. This work is licensed under the Creative Commons Attribution International License (CC BY 4.0).

http://creativecommons.org/licenses/by/4.0/ (c) (i) Open Access

\begin{abstract}
Flexible energy-storage devices play a critical role in the development of portable, flexible and wearable electronics. In addition, biological materials including plants or plant-based materials are known for their safety, biodegradability, biocompatibility, environmental benignancy, and low cost. With respect to these advances, a flexible alkaline zinc-manganese dioxide $\left(\mathrm{Zn}-\mathrm{MnO}_{2}\right)$ battery is fabricated with a kelp-based electrolyte in this study. To the best of our knowledge, pure kelp is utilized as a semi-solid electrolyte for flexible $\mathrm{Zn}-\mathrm{MnO}_{2}$ alkaline batteries for the first time, with which the as-assembled battery exhibited a specific capacity of $60 \mathrm{~mA} \cdot \mathrm{h}$ and could discharge for 120 h. Furthermore, the as-assembled $\mathrm{Zn}-\mathrm{MnO}_{2}$ battery can be bent into a ring-shape and power a light-emitting diode screen, showing promising potential for the practical application in the future flexible, portable and biodegradable electronic devices.
\end{abstract}

\section{Keywords}

Zinc-Manganese Dioxide Battery, Flexible Battery, Kelp-Based Electrolyte

\section{Introduction}

Recent progress in the development of portable, flexible and wearable electronics including wearable personal multiplayer, roll-up displays and smart clothes, is creating a brand new era to accelerate revolutionary changes in our lifestyles [1]-[6]. To meet the requirement of these versatile ubiquitous flexible and wearable devices, energy storage devices with high power-efficiency and excellent versatility to maintain their functionality are of great importance [7]-[13]. Among a variety of power supplies, zinc-manganese dioxide $\left(\mathrm{Zn}-\mathrm{MnO}_{2}\right)$ alkaline 
batteries have triggered great academic and technological interest in the field of flexible batteries because of the stable output voltage platform, high specific capacity, high battery safety, non-toxicity, low cost $\left(<\$ 90 \mathrm{kWh}^{-1}\right.$, compared with $\sim \$ 200 \mathrm{kWh}^{-1}$ for Li-ion batteries), and eco-friendliness [14] [15].

Traditional liquid-electrolyte-based $\mathrm{Zn}-\mathrm{MnO}_{2}$ alkaline batteries are usually fabricated with rigid and bulky configuration which cannot meet the flexible and portable requirements. Currently, quasi-solid-state polymer electrolytes play an important role in the development of flexible and portable $\mathrm{Zn}-\mathrm{MnO}_{2}$ alkaline batteries which are capable of maintaining battery performance as well as withstanding various deformations. For example, Gaikwad et al. [16] reported a stretchable $\mathrm{Zn}-\mathrm{MnO}_{2}$ battery based on an off-the-shelf compliant silver fabric substrate and a polyacrylic acid- $\mathrm{KOH}-\mathrm{ZnO}$ gel polymer electrolyte. Wang et al. [17] fabricated a flexible $\mathrm{Zn}-\mathrm{MnO}_{2}$ battery with a copolymer electrolyte film made from polyvinyl alcohol, polyacrylic acid and $\mathrm{KOH}$. In addition, Zeng et al. [18] and Su et al. [19] assembled flexible $\mathrm{Zn}-\mathrm{MnO}_{2}$ batteries using polyvinyl alcohol and cellulose-based polymer electrolytes respectively. Despite of the achievements so far, disposable electronic products (e.g., electronic wrinkle-free eye sticks) require a high frequency of battery replacement resulting in a large number of discarded batteries which are difficult to recycle and easy to burden the environment. Therefore, the aforementioned polymer materials-based electrolytes face the challenges of biodegradability to solve the accumulation problem of waste batteries.

In this respect, biological materials including plants or plant-based materials show promising potential owing to their high safety, environmental friendliness, low cost and biocompatibility. Among various biomaterials, kelp which is a kind of large seaweed (algae) has been widely used as food product and source for industrial production of soda, glass, and hydrocolloids [20]. However, few studies have investigated the kelp-based electrolytes for flexible $\mathrm{Zn}-\mathrm{MnO}_{2}$ batteries as well as the corresponding battery performances. Herein, to the best of our knowledge, pure kelp is utilized as a semi-solid electrolyte for flexible $\mathrm{Zn}-\mathrm{MnO}_{2}$ alkaline batteries for the first time. The structure and morphology of the pure kelp were characterized by X-Ray Diffraction (XRD) and scanning electron microscope (SEM) measurements. In addition, the cathode is fabricated by mixing $\mathrm{MnO}_{2}$, carbon powders, polyvinylidene fluoride (PVDF) (dissolved in Methyl-2-pyrrolidinone (NMP) in a ratio of 3:10) on a flexible copper film. The XRD, SEM and mapping characterizations were also proceeded to demonstrate the successful fabrication of the $\mathrm{MnO}_{2}$-based electrode. Furthermore, a layer-structured $\mathrm{Zn}-\mathrm{MnO}_{2}$ battery is obtained by laminating a pure kelp-based electrolyte between a zinc film anode and a same-sized $\mathrm{MnO}_{2}$-based cathode. Excitingly, the resultant $\mathrm{Zn}-\mathrm{MnO}_{2}$ battery can be bent into a ring-shape and power a light-emitting diode (LED) screen simultaneously, exhibiting promising potential for the practical application in flexible and portable electronic devices. This study aims to take the first step to investigate a pure biomaterial (i.e. kelps) as an electrolyte with non-toxicity, biodegradability, high safety, low-cost and eco-friendliness for 
the application of flexible $\mathrm{Zn}-\mathrm{MnO}_{2}$ batteries.

\section{Experimental Part}

\subsection{Materials and Preparation of Pure Kelp-Based Electrolyte Film}

The pure kelp-based electrolyte film was prepared with the dried kelps from the market. The dried kelps were first washed carefully to remove the small grains at surface and soaked in the deionized water. After a day of soaking, the dried kelps were swollen into wet kelps with a certain thickness. Then the wet kelp was soaked into a potassium hydroxide solution $(\mathrm{KOH})$ with a concentration of 6 $\mathrm{mol} / \mathrm{L}$ to absorb the alkaline solutions. With this method, the pure kelp-based electrolyte film was fabricated.

\subsection{Materials and Preparation of $\mathrm{MnO}_{2}$ Cathode}

$\mathrm{MnO}_{2}$ cathode was prepared with a coating method. First, the $\mathrm{MnO}_{2}$-based electrode paste was prepared by mixing $\mathrm{MnO}_{2}$ powders, carbon powders (XC-72), polyvinylidene fluoride (PVDF) (dissolved in Methyl-2-pyrrolidinone (NMP) in a ratio of 3:10) by a corundum grinding bowl for $30 \mathrm{~min}$. Then the as-prepared cathode paste was coated on a copper film by using a height adjustable applicator with thickness of $500 \mu \mathrm{m}$. The $\mathrm{MnO}_{2}$-based paste coated copper film was then transferred into an oven for $12 \mathrm{~h}$ under $70^{\circ} \mathrm{C}$. Finally, the $\mathrm{MnO}_{2}$ cathode was obtained.

\subsection{Materials Characterization}

In order to investigate the structure of the pure kelp-based electrolyte film and $\mathrm{MnO}_{2}$ cathode, X-Ray Diffraction (XRD) measurement was carried out with a Bruker/D8 X-ray diffractometer with $\mathrm{Cu} \mathrm{K}_{\alpha}$ radiation in the range of $2 \theta=10^{\circ}$ to $90^{\circ}$ and $2 \theta=10^{\circ}$ to $60^{\circ}$ respectively. In addition, in order to investigate the morphology and composition information of the pure kelp-based electrolyte film and $\mathrm{MnO}_{2}$ cathode, scanning electron microscopy (SEM) measurement was carried out with a $\mathrm{S} 4800$ which equipped with an energy-dispersive X-ray (EDX) analysis and elemental mapping. Due to the low electronic conductivity of the pure kelp, the freeze-dried kelp was sprayed with gold for $50 \mathrm{~s}$ before SEM characterization.

\subsection{Battery Electrochemical Measurements}

Flexible $\mathrm{Zn}-\mathrm{MnO}_{2}$ battery was assembled in a layered structure by laminating the kelp-KOH electrolyte between a zinc film anode $\left(0.3 \mathrm{~mm}, 30 \times 30 \mathrm{~mm}^{2}\right)$ and the as-prepared $\mathrm{MnO}_{2}$-based cathode $\left(30 \times 30 \mathrm{~mm}^{2}\right)$. A plastic film was used to enhance the integrity of the obtained sandwich-like $\mathrm{Zn}-\mathrm{MnO}_{2}$ battery which was also used as the packing material. The galvanostatic discharge performance was conducted employing a multi-channel battery testing system (LAND CT2001A). The current densities used in this study were normalized to the active materials 
$(0.5 \mathrm{~mA}, 0.0782 \mathrm{~g})$ or electrode area $\left(0.5 \mathrm{~mA}, 30 \times 30 \mathrm{~mm}^{2}\right)$.

\section{Results and Discussion}

As mentioned, biological materials including plants or plant-based materials are advantageous because of their high safety, environmental friendliness, low-cost, biodegradability and biocompatibility. In addition, biodegradable biomass is a promising material for the application of disposable electronic products. Among plenty of biomaterials, kelp is a kind of large seaweed (algae) which can be used in the field of food product and source for industrial production of soda, glass, and hydrocolloids [20]. Figure 1 shows the photographs of the dried kelp bought from the market and the wet kelp after soaking in the deionized water for a day. Before soaking into $6 \mathrm{~mol} / \mathrm{L} \mathrm{KOH}$ electrolyte solution, the pure kelp was freeze-dried with a freeze dryer and its structure information was identified by XRD measurement. As shown in Figure 2, XRD pattern of the dried kelp exhibits a main peak at $29.4^{\circ}$ and several small peaks at $23.1^{\circ}, 35.9^{\circ}, 39.4^{\circ}, 43.2^{\circ}, 47.1^{\circ}$, and $47.5^{\circ}$. These peaks correspond to (104), (012), (110), (11 $\left.\overline{3}\right),(202),(024)$, and (018) planes of the $\mathrm{CaCO}_{3}$ (JCPD \#47-1743), indicating the existence of element $\mathrm{Ca}$ in the kelp which is carbonized in air. The existence of $\mathrm{Ca}$ is in agreement with the fact that kelps accumulate many minerals from the seawater over their lifetime, providing a rich source of calcium, sodium, magnesium, potassium, and other rare elements [21] [22]. To further investigate the ingredient and morphology information of the kelp, Figure 3 shows SEM image, EDX analysis, and elemental mapping images of $\mathrm{C}, \mathrm{O}$ of the dried pure kelp. Due to the low electronic conductivity of the pure kelp, the freeze-dried kelp was sprayed with gold for $50 \mathrm{~s}$ before SEM characterization. As biomass, the kelp consists of many cells which are bubble-like bumps in the case of freeze-drying as shown in Figure 3(a). The EDX result suggests the existence of carbon (49.99 wt\%), oxygen (43.45 wt\%), calcium (2.49 wt\%), magnesium (1.44 wt\%), and potassium (0.83 $\mathrm{wt} \%)$, sodium (0.36 wt\%). Owing to the low concentration of sodium, magnesium, and potassium as well as the amorphous phase of the biological skeleton, the only carbonate $\left(\mathrm{CaCO}_{3}\right)$ is detected by the XRD measurement (Figure 2). Moreover, the elemental mapping results in Figures $3(\mathrm{c})$-(e) show the even distribution element carbon and oxygen of the dried pure kelp, confirming its biological skeleton.
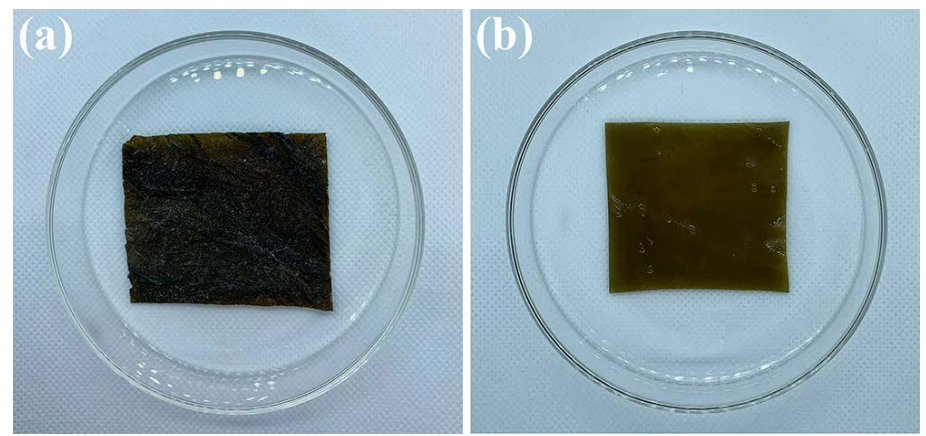

Figure 1. Photographs of (a) the dried kelp bought from the market, and (b) the wet kelp after soaking in the deionized water for a day. 


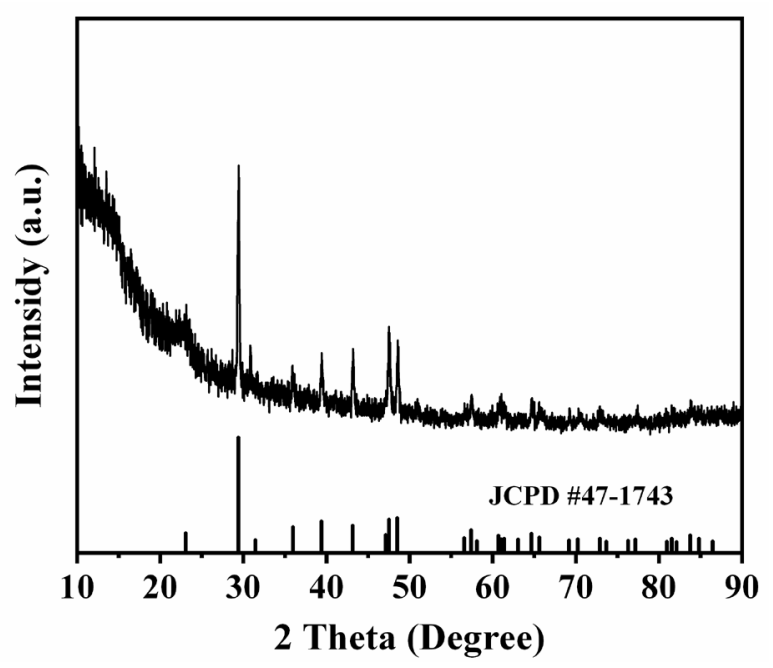

Figure 2. XRD pattern of the dried kelp before soaking into $6 \mathrm{~mol} / \mathrm{L} \mathrm{KOH}$.
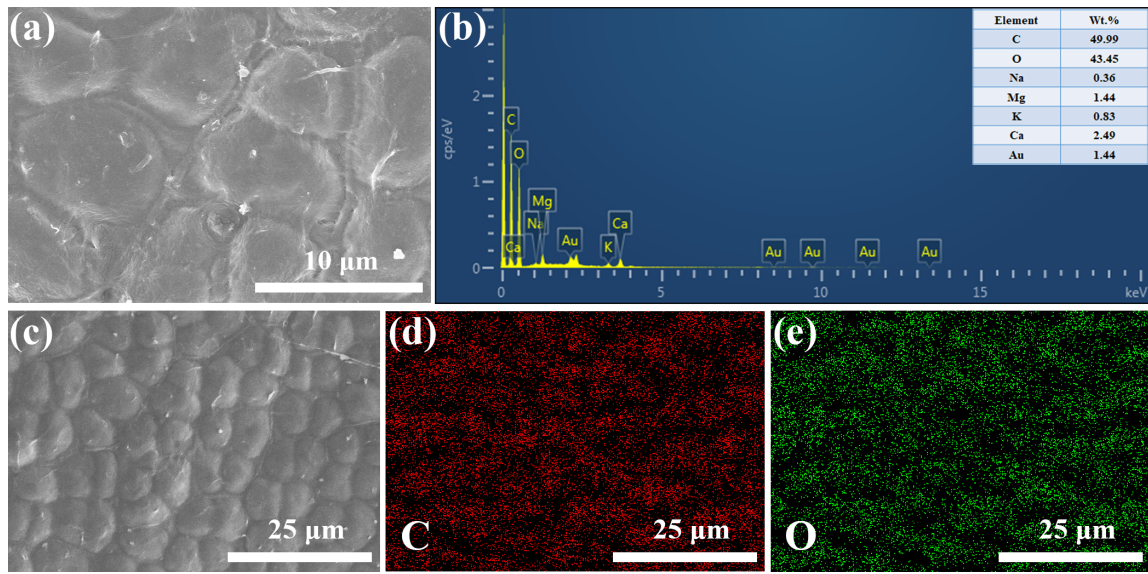

Figure 3. (a) SEM image, (b) EDX analysis, (c)-(e) elemental mapping images of C, O of the dried pure kelp.

$\mathrm{MnO}_{2}$-based cathode for $\mathrm{Zn}-\mathrm{MnO}_{2}$ alkaline battery was prepared by coating the electrode paste containing $\mathrm{MnO}_{2}$ powders, carbon powders, PVDF (dissolved in NMP in a ratio of 3:10) on a copper film with a thickness of $500 \mu \mathrm{m}$. The structure of the obtained $\mathrm{MnO}_{2}$-based cathode was characterized by XRD measurement as shown in Figure 4. The two peaks at $43.3^{\circ}$ and $50.4^{\circ}$ are related to the (111) and (200) planes of $\mathrm{Cu}$ corresponding to the $\mathrm{Cu}$ film substrate of the as-prepared cathode (JCPD \#04-0836). In addition, XRD pattern of the $\mathrm{MnO}_{2}$-based cathode exhibits several small peaks at $37.1^{\circ}, 42.4^{\circ}$, and $56^{\circ}$ which correspond to (110), (101), and (102) planes of the $\mathrm{MnO}_{2}$ (JCPD \#30-0820) respectively, showing successful adhesion of the $\mathrm{MnO}_{2}$-based paste onto the substrate. Moreover, the morphologic information of the fabricated electrode is obtained by SEM measurement in Figure 5(a). The active layer of the cathode is composed of $\mathrm{MnO}_{2}$ and carbon particles, which are bound to form electrical pathways throughout the surface providing good electrical conductivity. EDX analysis further identified the composition of the electrode with $\mathrm{C}, \mathrm{O}$ and $\mathrm{Mn}$. 


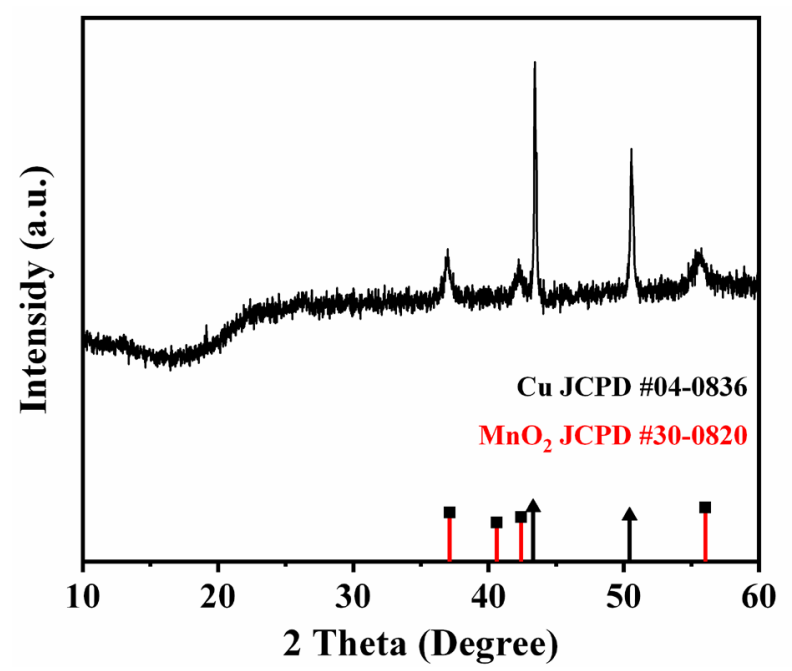

Figure 4. XRD pattern of the $\mathrm{MnO}_{2}$-based cathode (fabricated by coating the $\mathrm{MnO}_{2} / \mathrm{C} / \mathrm{PVDF} / \mathrm{NMP}$ on a $\mathrm{Cu}$ film).
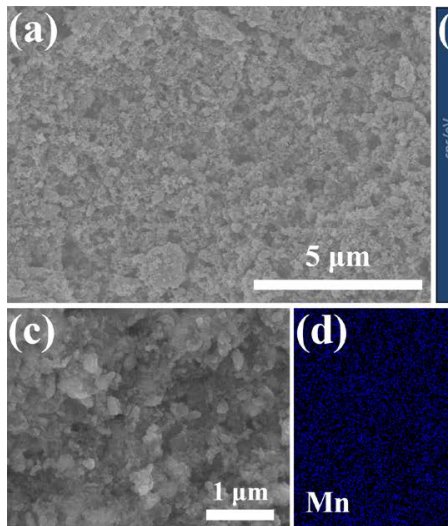
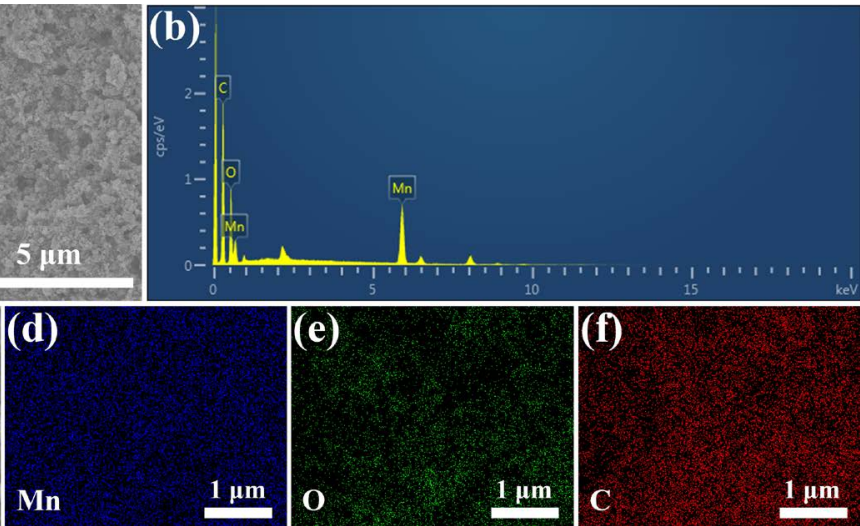

Figure 5. (a) SEM image, (b) EDX analysis, (c)-(f) elemental mapping images of $\mathrm{Mn}, \mathrm{O}$, $\mathrm{C}$ of $\mathrm{MnO}_{2}$-based cathode.

Figures 5(c)-(f) are elemental mapping images of $\mathrm{Mn}, \mathrm{O}, \mathrm{C}$ of $\mathrm{MnO}_{2}$-based cathode, indicating uniform distribution of the active materials of the electrode. Therefore, the resultant $\mathrm{MnO}_{2}$-based cathode with good adhesion and uniform distribution of the active material paste onto the substrate is critical for the battery performance of the flexible $\mathrm{Zn}-\mathrm{MnO}_{2}$ battery.

Based on the prepared pure kelp immersed in the $\mathrm{KOH}$ electrolyte solution previously and the obtained $\mathrm{MnO}_{2}$-based cathode, a flexible sandwich-type $\mathrm{Zn}-\mathrm{MnO}_{2}$ battery is fabricated. As illustrated in Figure 6(a), the flexible $\mathrm{Zn}-\mathrm{MnO}_{2}$ battery is assembled with a zinc film, an as-prepared $\mathrm{MnO}_{2}$-based electrode paste coated $\mathrm{Cu}$ film cathode by laminating a pure kelp- $\mathrm{KOH}$ electrolyte membrane in between. A plastic film was used to enhance the integrity of the battery which was also used as the packing material. Figure $6(\mathrm{~b})$ shows the photograph of the assembled $\mathrm{Zn}-\mathrm{MnO}_{2}$ battery. Figures 6(c)-(e) further demonstrates the good flexibility of each component of the battery which plays an essential role in the battery performance under bending deformation. Crosse-section SEM of the kelp elec- 
trolyte-based $\mathrm{Zn}-\mathrm{MnO}_{2}$ battery (Figure 7) is exhibited to illustrate its sandwich structure as well as the good battery integrity. Discharge curve of $\mathrm{Zn}-\mathrm{MnO}_{2}$ battery with the kelp-based electrolyte at a constant current density of $0.22 \mathrm{~mA}$ $\mathrm{cm}^{-2}\left(\sim 6.4 \mathrm{~mA} \cdot \mathrm{g}^{-1}\right)$ is presented in Figure 8, which exhibits a specific capacity of $60 \mathrm{~mA} \cdot \mathrm{h}\left(\sim 6.67 \mathrm{~mA} \cdot \mathrm{h} \cdot \mathrm{cm}^{-2}, \sim 767.3 \mathrm{~mA} \cdot \mathrm{h} \cdot \mathrm{g}^{-1}\right)$. Excitingly, due to the good electrolyte retention ability of the kelp-based electrolyte, integrated battery assembly, and successful package method, the resultant $\mathrm{Zn}-\mathrm{MnO}_{2}$ battery could discharge for $120 \mathrm{~h}$ (Figure 8), much longer than that of previously reported studies [17].

Benefiting from the good flexibility of each component of the as-fabricated $\mathrm{Zn}-\mathrm{MnO}_{2}$ battery as well as its promising battery performances (Figure 8), the kelp-based battery shows promising potential in practical applications. Figure 9(a) presents the open circuit potential $(1.408 \mathrm{~V})$ of a homemade flexible sandwich-type

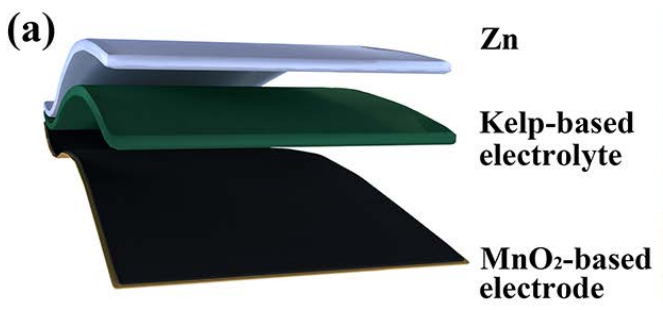

(c)

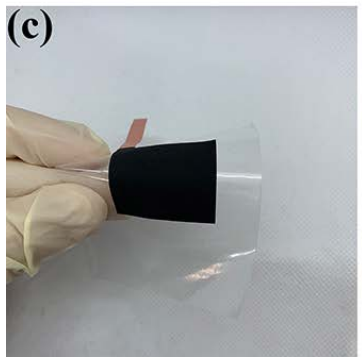

(d)

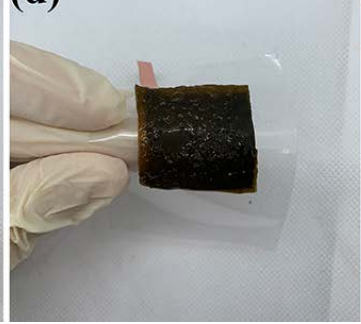

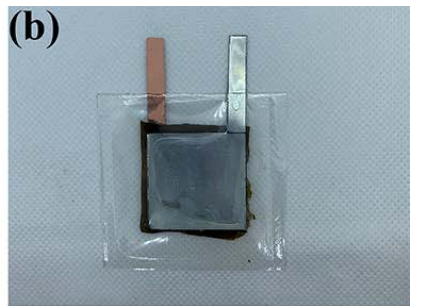

(e)

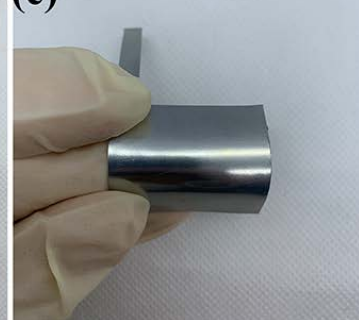

Figure 6. (a) Illustration of the battery structure of flexible sandwich-type $\mathrm{Zn}-\mathrm{MnO}_{2}$ battery fabricated with zinc film, $\mathrm{MnO}_{2}$-based cathode and pure kelp-based electrolyte membrane. (b) Photograph of the assembled $\mathrm{Zn}-\mathrm{MnO}_{2}$ battery $\left(30 \times 30 \mathrm{~mm}^{2}\right)$. Flexible demonstration of (c) $\mathrm{MnO}_{2}$-based cathode, (d) pure kelp-based electrolyte, and (e) zinc film.

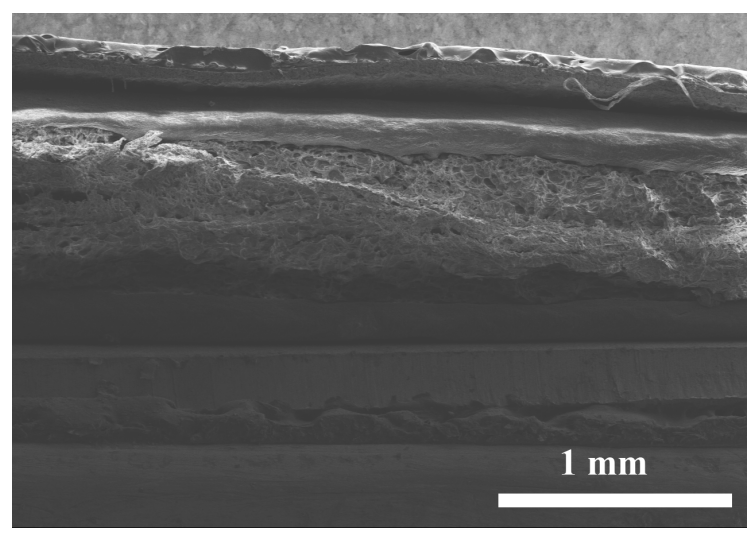

Figure 7. Crosse-section SEM of the kelp electrolyte-based $\mathrm{Zn}-\mathrm{MnO}_{2}$ battery. 


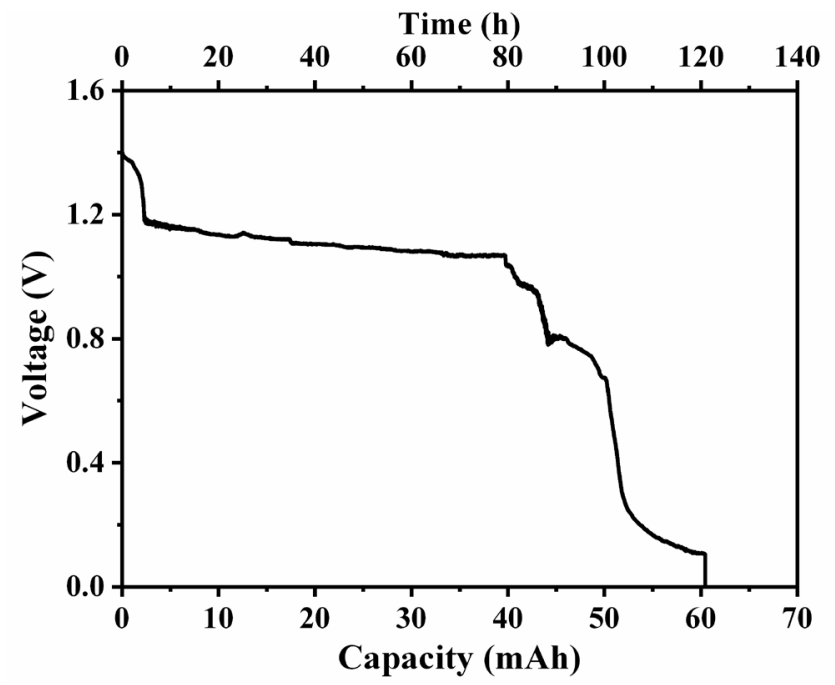

Figure 8. Discharge performance of the kelp electrolyte-based $\mathrm{Zn}-\mathrm{MnO}_{2}$ battery based on capacity and working time.

(a)

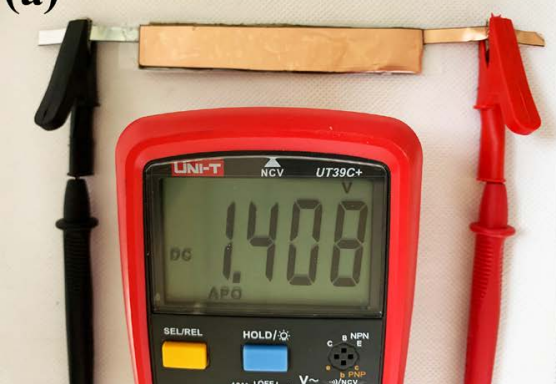

(b)

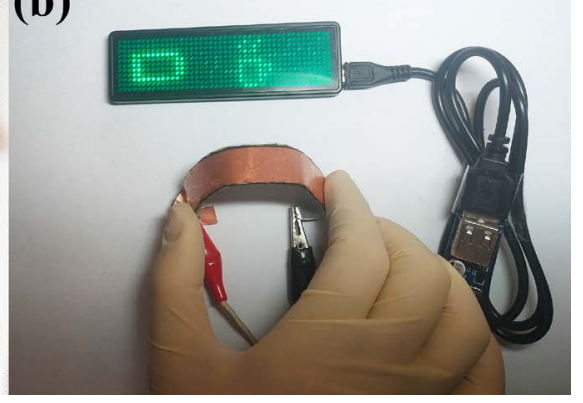

Figure 9. (a) Demonstration of the open circuit potential of the homemade flexible sandwich-type $\mathrm{Zn}-\mathrm{MnO}_{2}$ battery fabricated with zinc film, $\mathrm{MnO}_{2}$-based cathode and pure kelp-based electrolyte membrane. (b) Demonstration of two of the fabricated $\mathrm{Zn}-\mathrm{MnO}_{2}$ battery in series under bending condition powering an LED screen.

$\mathrm{Zn}-\mathrm{MnO}_{2}$ battery fabricated with zinc film, $\mathrm{MnO}_{2}$-based cathode, and the pure kelp-based electrolyte membrane. In addition, to further exemplify the viability for flexible and wearable applications, Figure 9 (b) displays two of the fabricated $\mathrm{Zn}-\mathrm{MnO}_{2}$ batteries in series under bending condition which can power an LED screen. All of these results conclusively demonstrate the promising application of our fabricated flexible $\mathrm{Zn}-\mathrm{MnO}_{2}$ battery in flexible and wearable electronics.

\section{Conclusion}

In conclusion, a flexible alkaline $\mathrm{Zn}-\mathrm{MnO}_{2}$ battery is fabricated with a kelp-based electrolyte for the first time. In addition, XRD and SEM measurements on the pure kelp for the application of electrolytes are investigated for the first time to the best of our knowledge. Interestingly, benefiting from the good electrolyte retention capability of the pure kelp, the as-assembled $\mathrm{Zn}-\mathrm{MnO}_{2}$ battery exhibits a good specific capacity of $60 \mathrm{~mA} \cdot \mathrm{h}$ which can discharge for $120 \mathrm{~h}$. Furthermore, each component of the battery shows outstanding mechanical flexibility, with 
which the resultant $\mathrm{Zn}-\mathrm{MnO}_{2}$ battery exhibits a relatively high OCP of $\sim 1.4 \mathrm{~V}$ and can be bent into a ring-shape and power an LED screen. This study sheds light on the exploration of investigating a pure biomaterial (i.e. kelps) as electrolyte materials with non-toxicity, biodegradability, high safety, low cost and eco-friendliness for the application of flexible $\mathrm{Zn}-\mathrm{MnO}_{2}$ batteries. The successful construction of a kelp-based flexible $\mathrm{Zn}-\mathrm{MnO}_{2}$ battery shows promising potential for next-generation power supplies for wearable electronic devices.

\section{Conflicts of Interest}

The authors declare no conflicts of interest regarding the publication of this paper.

\section{References}

[1] Lee, H.M., Choi, S.Y., Jung, A. and Ko, S.H. (2013) Highly Conductive Aluminum Textile and Paper for Flexible and Wearable Electronics. Angewandte Chemie International Edition, 52, 7718-7723. https://doi.org/10.1002/anie.201301941

[2] Stoppa, M. and Chiolerio, A. (2014) Wearable Electronics and Smart Textiles: A Critical Review. Sensors, 14, 11957-11992. https://doi.org/10.3390/s140711957

[3] Bao, Z.N. and Chen, X.D. (2016) Flexible and Stretchable Devices. Advanced Materials, 28, 4177-4179. https://doi.org/10.1002/adma.201601422

[4] Zhao, Z.Q., Fan, X.Y., Ding, J., Hu, W.B., Zhong, C. and Lu, J. (2019) Challenges in Zinc Electrodes for Alkaline Zinc-Air Batteries: Obstacles to Commercialization. ACS Energy Letters, 4, 2259-2270. https://doi.org/10.1021/acsenergylett.9b01541

[5] Fan, X.Y., Liu, J., Song, Z.S., Han, X.P., Deng, Y.D., Zhong, C. and Hu, W.B. (2019) Porous Nanocomposite Gel Polymer Electrolyte with High Ionic Conductivity and Superior Electrolyte Retention Capability for Long-Cycle-Life Flexible Zinc-Air Batteries. Nano Energy, 56, 454-462. https://doi.org/10.1016/j.nanoen.2018.11.057

[6] Li, M., Liu, B., Fan, X.Y., Liu, X.R., Liu, J., Ding, J., Han, X.P., Deng, Y.D., Hu, W.B. and Zhong, C. (2019) Long-Shelf-Life Polymer Electrolyte Based on Tetraethylammonium Hydroxide for Flexible Zinc-Air Batteries. ACS Applied Materials \& Interfaces, 11, 28909-28917. https://doi.org/10.1021/acsami.9b09086

[7] He, Y.H., Matthews, B., Wang, J.Y., Song, L., Wang, X.X. and Wu, G. (2018) Innovation and Challenges in Materials Design for Flexible Rechargeable Batteries: From $1 \mathrm{D}$ to 3D. Journal of Materials Chemistry $A, 6,735-753$. https://doi.org/10.1039/C7TA09301B

[8] Wang, X.F., Lu, X.H., Liu, B., Chen, D., Tong, Y.X. and Shen, G.Z. (2014) Flexible Energy-Storage Devices: Design Consideration and Recent Progress. Advanced Materials, 26, 4763-4782. https://doi.org/10.1002/adma.201400910

[9] Dong, L.B., Xu, C.J., Li, Y., Pan, Z.Z., Liang, G.M., Zhou, E.L., Kang, F.Y. and Yang, Q.H. (2016) Breathable and Wearable Energy Storage Based on Highly Flexible Paper Electrodes. Advanced Materials, 28, 9313-9319. https://doi.org/10.1002/adma.201602541

[10] Liu, X.R., Yuan, Y.F., Liu, J., Liu, B., Chen, X., Ding, J., Han, X.P., Deng, Y.D., Zhong, C. and Hu, W.B. (2019) Utilizing Solar Energy to Improve the Oxygen Evolution Reaction Kinetics in Zinc-Air Battery. Nature Communications, 10, 4767. https://doi.org/10.1038/s41467-019-12627-2

[11] Sun, Y.T., Liu, X.R., Jiang, Y.M., Li, J., Ding, J., Hu, W.B. and Zhong, C. (2019) Re- 
cent Advances and Challenges in Divalent and Multivalent Metal Electrodes for Metal-Air Batteries. Journal of Materials Chemistry A, 7, 18183-18208. https://doi.org/10.1039/C9TA05094A

[12] Fan, X., Liu, X., Hu, W., Zhong, C. and Lu, J. (2019) Advances in the Development of Power Supplies for the Internet of Everything. InfoMat, 1, 130-139. https://doi.org/10.1002/inf2.12016

[13] Ding, J., Liu, Z., Liu, X.R., Liu, J., Deng, Y.D., Han, X.P., Zhong, C. and Hu, W.B. (2019) Mesoporous Decoration of Freestanding Palladium Nanotube Arrays Boosts the Electrocatalysis Capabilities toward Formic Acid and Formate Oxidation. Advanced Energy Materials, 9, Article ID: 1900955. https://doi.org/10.1002/aenm.201900955

[14] He, B., Zhang, Q.C., Li, L.H., Sun, J., Man, P., Zhou, Z.Y., Li, Q.L., Guo, J.B., Xie, L.Y., Li, C.W., Wang, X.N., Zhao, J.X., Zhang, T. and Yao, Y.G. (2018) High-Performance Flexible All-Solid-State Aqueous Rechargeable $\mathrm{Zn}-\mathrm{MnO}_{2}$ Microbatteries Integrated with Wearable Pressure Sensors. Journal of Materials Chemistry A, 6, 14594-14601. https://doi.org/10.1039/C8TA05862H

[15] Seo, J.K., Shin, J., Chung, H., Meng, P.Y., Wang, X.F. and Meng, Y.S. (2018) Intercalation and Conversion Reactions of Nanosized Beta- $\mathrm{MnO}_{2}$ Cathode in the Secondary $\mathrm{Zn} / \mathrm{MnO}_{2}$ Alkaline Battery. Journal of Physical Chemistry C, 122, 11177-11185. https://doi.org/10.1021/acs.jpcc.7b11685

[16] Gaikwad, A.M., Zamarayeva, A.M., Rousseau, J., Chu, H., Derin, I. and Steingart, D.A. (2012) Highly Stretchable Alkaline Batteries Based on an Embedded Conductive Fabric. Advanced Materials, 24, 5071-5076. https://doi.org/10.1002/adma.201201329

[17] Wang, Z., Wu, Z., Bramnik, N. and Mitra, S. (2014) Fabrication of High-Performance Flexible Alkaline Batteries by Implementing Multiwalled Carbon Nanotubes and Copolymer Separator. Advanced Materials, 26, 970-976. https://doi.org/10.1002/adma.201304020

[18] Zeng, Y.X., Zhang, X.Y., Meng, Y., Yu, M.H., Yi, J.N., Wu, Y.Q., Lu, X.H. and Tong, Y.X. (2017) Achieving Ultrahigh Energy Density and Long Durability in a Flexible Rechargeable Quasi-Solid-State $\mathrm{Zn}-\mathrm{MnO}_{2}$ Battery. Advanced Materials, 29, Article ID: 1700274. https://doi.org/10.1002/adma.201700274

[19] Su, S.Y., Xu, Y., Wang, Y., Wang, X.Y., Shi, L., Wu, D., Zou, P.C., Nairan, A., Lin, Z.Y., Kang, F.Y. and Yang, C. (2019) Holey Nickel Nanotube Reticular Network Scaffold for High-Performance Flexible Rechargeable $\mathrm{Zn} / \mathrm{MnO}_{2}$ Batteries. Chemical Engineering Journal, 370, 330-336. https://doi.org/10.1016/j.cej.2019.03.138

[20] Zhang, Y.F., Jiang, H.M., Wang, Q.S., Zheng, J.Q. and Meng, C.G. (2018) Kelp-Derived Three-Dimensional Hierarchical Porous N, O-Doped Carbon for Flexible Solid-State Symmetrical Supercapacitors with Excellent Performance. Applied Surface Science, 447, 876-885. https://doi.org/10.1016/j.apsusc.2018.04.061

[21] Qin, Y. (2018) Bioactive Seaweeds for Food Applications: Natural Ingredients for Healthy Diets. Academic Press, Cambridge.

[22] Li, J., Liu, K., Gao, X., Yao, B., Huo, K.F., Cheng, Y.L., Cheng, X.F., Chen, D.C., Wang, B., Sun, W.M., Ding, D., Liu, M.L. and Huang, L. (2015) Oxygen- and Nitrogen-Enriched 3D Porous Carbon for Supercapacitors of High Volumetric Capacity. ACS Applied Materials \& Interfaces, 7, 24622-24628.

https://doi.org/10.1021/acsami.5b06698 